\title{
Simulation of Double Walled Pipe Impact to Crude Oil Flow in Subsea Pipeline System
}

\author{
Dhimas Permadi ${ }^{1}$ Sutopo Purwono Fitri ${ }^{2}$, Wolfgang Busse ${ }^{3}$
}

\begin{abstract}
Crude oil contains mixed of hydrocarbons, the most commonly found molecules are alkanes (paraffins), cycloalkanes (naphthenes), aromatic hydrocarbons, or more complicated chemicals. In the process of taking crude oil in subsea pipeline system with depth 1200 meters , the contents of crude oil like sulfur, paraffin, asphalt could deposit in the wall of the pipe because of the different temperature between crude oil and wall of the pipe. The deposition can make blockage to the pipe and cause crude oil flow be slow or stop. In this bachelor thesis, will be design double walled pipe for Subsea pipeline system with depth 1200 meters and simulation double walled pipe to knowing the impact of double walled pipe to crude oil flow in Subsea with depth 1200 meters. Hope it can keep stabilize the temperature between crude oil and wall of the pipe when taking crude oil process, with the result that no deposition occurs and cause no blockage in the pipe and the crude oil flow will steady.
\end{abstract}

Keywords—Double Walled Pipe, Crude Oil, Subsea Pipeline System

\section{INTRODUCTION}

\section{Crude oil is a mixture of comparatively volatile}

liquid hydrocarbons (compounds composed mainly of hydrogen and carbon), though it also contains some nitrogen, sulfur, and oxygen. Crude oil also is categorized as "sweet" or "sour" depending on the level of sulfur, which occurs either as elemental sulfur or in compounds such as hydrogen sulfide. In the process of taking crude oil in subsea pipeline system with depth 1200 meters, the contents of crude oil like paraffin, asphalt, sulfur coulddeposit in the wall of the pipe because of the different temperature between crude oil and wall of the pipe.

Deposition in oil pipeline is one of the major problems facing in the crude oil transportation flow line from the offshore to onshore through pipe. The deposition occurs because of the crude oil fluids temperature is decrease during the transportation process and cause solidification of the components of crude oil. The deposition is considered to be one of critical problem causing all these impurities, lead to blockage of pipelines thereby restricting the flow, and made the production losses.In general, this problem usually remove by pigging (mechanical cleaning).

In this bachelor thesis, will be design the double walled pipe to offering the alternative solution for pipeline system in subsea with depth 1200 meter ,and will be simulate the double walled impact to crude oil flow in Subsea pipeline system.

By using double walled pipe, hope that the temperature crude oil keep stabilize and there is no deposition that cause blockage in pipeline system of taking crude oil process, so the crude oil flow will be steady and to decrease using pigging for cleaning the

Dhimas Permadi, Departmen of Marine Engineering, Institut Teknologi Sepuluh Nopember, Surabaya 60111, Indonesia, Email : dhimaspermadi94@gmail.com

Sutopo Purwono Fitri, Departmen of Marine Engineering, Institut Teknologi Sepuluh Nopember, Surabaya 60111, Indonesia, Email :sutopopf@gmail.com

Wolfgang Busse, Faculty of Engineering, Hochshule Wismar, 23952 Wismar, Germany, Email : wolfgang.busse@hs-wismar.de deposition in the pipe cause of the deposition from content of crude oil.

\section{LITERATURE REVIEW}

\section{A. Double Walled Pipe}

Double Walled Pipe is more complex than single pipe because the systems have been adopted for both onshore and offshore industrial applications for thermal insulation, leak containment and protection of flowlines [1].

Dr. Alan Murray (an adjunct professor in the Schulich School of Engineering at the University of Calgary) explained that double-walled pipelines may be used when there are large differences in temperature between the flowing liquid and its surroundings. For instance, some offshore pipelines carry a waxy crude, which would solidify if it were exposed to the colder temperatures of seawater. The insulation afforded by using aerogel (which has a very low thermal conductivity) in the gap between the layers of pipe keeps the crude at an appropriate temperature [2].

\section{B. Subsea Pipelines System}

Subsea sea pipelines are used for the transportation of oil and gas over long distances.In the design of Subsea pipelines, there are numerous factors which must be considered, any one of which could be the limiting state in the design which prevents light-weighting [3].

\section{Design Pipe}

The object of the design process for a pipeline is to determine, based on given operating parameters, the optimum pipeline size parameters. These parameters include:

C.1 Wall Thickness and Material Grade Verification.

The wall thickness verification is performing in accordance with the requirement of ASME B31.4, ASME B31.8, and API RP 1111 on satisfying the following requirements:

a. Internal Pressure Containment

The formula used to calculate the nominal wall thickness required to contain internal pressure is using 
the hoop stress analyses in accordance with ASME B31.8.

The hoop stress due to difference between internal and external pressure shall not exceed the value below:

$S_{h} \leq F_{1} . S . T$

$S_{h}=\frac{\left(P_{i}-P_{e}\right) \cdot D}{2 . t_{\min }}$

From above,

$t_{\min }=\frac{\left(P_{i}-P_{e}\right) \cdot D}{2 \cdot S_{h}}$

$t_{r}=t_{\text {min }}+t_{c o r r}+t_{f a b}$

b. Collapse due to External Pressure

As per the API RP 1111, pipe collapse may occur when the external pressure caused by hydrostatic pressure due to water depth exceeds the internal pressure and is sufficient to buckle a pipeline. The collapse pressure of the pipe must exceed the net external pressure everywhere along the pipeline as follows:

$\left(\mathrm{P}_{0}-\mathrm{P}_{\mathrm{i}}\right) \leq \mathrm{f}_{\mathrm{o}} \cdot \mathrm{P}_{\mathrm{c}}$

The following equation are used to approximate the collapse pressure:

$\mathrm{P}_{\mathrm{c}}=\frac{\mathrm{P}_{\mathrm{y}} \cdot \mathrm{P}_{\mathrm{e}}}{\left(\mathrm{P}_{\mathrm{y}}{ }^{2}+\mathrm{P}_{\mathrm{e}}{ }^{2}\right)^{0.5}}$

$\mathrm{P}_{\mathrm{y}}=2 \cdot \mathrm{S} \cdot\left(\frac{t_{\min }}{\mathrm{D}}\right)$

$P_{e}=2 \cdot E \cdot \frac{\left(\frac{t_{\min }}{D}\right)^{3}}{\left(1-v^{2}\right)}$

c. Buckling due to Combined Bending and External Pressure

As per the API RP 1111, combined bending strains and external pressure load should satisfy the following:

$\frac{\varepsilon}{\varepsilon_{b}}=\frac{\left(P_{i}-P_{e}\right)}{P_{c}} \leq g(\delta)$

To avoid buckling, bendig strains should be limited as follows:

$$
\begin{aligned}
& \varepsilon \leq f_{1} \varepsilon_{1} \\
& \varepsilon \leq f_{2} \varepsilon_{2}
\end{aligned}
$$

\section{d. Propagation Buckling}

As per API RP 1111, a buckle resulting from excessive bending or another cause may propagate. Offshore hydrocarbon pipeline may fail by propagation buckle caused by the hydrostatic pressure of seawater on a pipeline with a diameter to wall thickness $(\mathrm{D} / \mathrm{t})$ ratio is too high. For submarine pipeline, since the hydrostatic pressure is the force that causes a buckle to propagate, it's useful to estimate the buckle propagation pressure. The minimum wall thickness to resist propagation buckle must be satisfy with following equation:

$P_{0}-P_{1} \geq f_{p} P_{p}$

$P_{p}=24 \cdot S \cdot\left[\frac{t}{D}\right]^{24}$

\section{C.2 On Bottom Stability Design}

The offshore pipeline will be designed to be stable on the seabed against wave and bottom current.
The lateral and vertical on-bottom stability of the offshore pipeline will be based on analysis that defines the pipeline design parameters required to prevent any pipeline movement on the seabed throughout the design life of the pipeline.The on-bottom stability analysis is performed based on DNV-RP-F109.

a. Pipeline Vertical Stability

- Vertical Stability in Water

The installation phase relates to the period of the time after installation when the pipeline is resting on seabed prior to commissioning.

- Vertical Stability on and in soil

Exposed lines resting directly on the seabed should be checked for possible sinking.

b. Absolute Lateral Static Stability

This section gives an absolute static requirement for lateral on-bottom pipelines based on static equilibrium of forces that ensures that the resistance of the pipe against motion is sufficient to withstand maximum hydrodynamic loads during a sea state.

b.1 Design Criterion

A pipeline can be considered to satisfy the absolute static stability requirement if:

$\gamma_{s c} \cdot \frac{F_{y}{ }^{\prime}}{\mu \cdot w_{s}+F_{R}} \leq 1.0$
$\gamma_{s c} \cdot \frac{F_{z}{ }^{\prime}}{w_{s}} \leq 1.0$

\section{b.2 Safety Factor}

For absolute stability in regular sea states, the safety factors $\gamma \mathrm{sc}$ of 1.0 and 1.4 are used for installation and operation condition respectively, refer to Table 3-5 of DNV RP - F109.

\section{b.3 Loads}

Peak horizontal and vertical loads are:

$$
F_{y}{ }^{\prime}=r_{t o t, y} \cdot \frac{1}{2} \cdot \rho_{w} \cdot D \cdot C_{y}{ }^{\prime} \cdot\left(U^{\prime}+V^{\prime}\right)^{2} \text { (с.1.1) }
$$

and

$F_{z}^{\prime}=r_{t o t, z} \cdot \frac{1}{2} \cdot \rho_{w} \cdot D \cdot C_{y}{ }^{\prime} \cdot\left(U^{\prime}+V^{\prime}\right)^{2}$ (с.1.2)

\section{C.3 Thermal Expansion Analysis}

Pipeline thermal expansion analysis for both operating and hydrotest conditions shall be carried out.

a. Strain Due to Pressure End Cap

The end cap strain is caused by the internal pressure of the fluid in the pipeline acting at an effectively "closed" end of a pipeline, such as a bend. The strain is approximately as per following formula, this strain acts over the whole length of the pipeline

$\varepsilon_{E}=\frac{\pi}{4} \cdot \frac{\left[P_{i n} D_{i}^{2}-P_{o} D_{o}^{2}\right]}{E A_{s}}$

\section{b. Strain Due to Poisson Effect}

The Poisson strain is a result of the action of the hoop stress, which radially expands the pipeline. According to Poisson's effect, a longitudinal strain is developed and is given by:

$\varepsilon_{v}=v \cdot \frac{\left[P_{\text {in }} D_{i}-P_{o} D_{o}\right]}{2 \cdot E \cdot t_{2}}$ 
c. Strain Due to Temperature

When a pipeline is installed, its length in an unstressed condition is governed by the ambient temperature of the seawater. Any increase in this temperature will cause thermal expansion given by:

$\varepsilon_{T}=\alpha \cdot \Delta T$

$$
\Delta T_{x}=T_{x}-T_{\text {ins }}
$$

\section{d. Frictional Strain}

When a pipe moves, a frictional resistance is developed between the pipe and seabed, tending to oppose the movement. The friction strain is expressed in different equations for unburied pipeline and buried pipeline.

$\varepsilon_{f}=\frac{\mu_{a} w x}{A_{s} E}$

\section{e. Total Applied Strain}

The total applied strain acting along the pipeline length is the summation of the applied strains described above, i.e.

$$
\varepsilon_{\text {tot }}=\varepsilon_{E}+\varepsilon_{v}+\varepsilon_{T}+\varepsilon_{f}
$$

\section{f. Anchor Point}

A certain point along the pipeline, the frictional resistance strain is large enough to equal the applied strain, forming an anchor point beyond which pipeline movement is prevented. As friction is a "passive" reaction, it is only mobilized to an amount less than, or equal to, the applied strain. The location of the anchor point can be determined by equating the applied force to the frictional force, therefore :

$$
L_{A}=\frac{\varepsilon_{\text {tot }} \cdot A_{s} \cdot E}{w}
$$

\section{C.4 Chatodic Protection Verification}

Cathodic protection design verification of proposed EPCI-1 pipelines shall be in accordance with DNV RP F103 - 2010 and ISO 15589-2 - 2004. In the cathodic protection design verification, calculations will be carried out to ensure sufficient anodes are available to provide total current needed to protect the pipeline during its design life.

\section{C.5 Allowable Free Span Calculation}

The subsea pipeline free span may be constructed to unforeseen condition on the seabed or develop due to seabed instability or sediment transport on the seabed. Free span represent of critical section in the pipeline system where high bending stress may develop and combination with hoop stress from the internal pressure, and temperature induced stresses, an increased risk for yielding or local buckling of the pipeline wall exist [4].

\section{Heat Transfer}

Heat transfer are a device that transfer the heat between two fluids of different temperatures that are separated by a solid wall. The temperature gradient, or the differences in temperature facilitate this transfer of heat. Heat transfer divided by three modes, they are conduction, convection, and radiation.

\section{D.1 Conduction}

Conduction is the heat transfer process that will occur across the medium. It means that the process of transfer energy is coming from more energetic particles of a substance to the adjacent less energetic ones as a result of interactions between particles.

$q=-k \frac{d T}{d x}$

\section{D.2 Convection}

Convection is the mode of energy transfer between a solid surface and the adjacent liquid or gas that is in motion, and it involves the combined effects of conduction and fluid motion.Convection heat transfer process have two kinds, there are:

- Forced Convection

The fluid is forced to flow over the surface by external equipment, such as fan, pump, or the wind.

- Natural/Free Convection

Natural or free convection means that the fluid motion which is caused by the buoyancy forces that are induced by density differences due to the variation of temperature in the fluid.

$q=h\left(T_{s}-T_{\infty}\right)$

\section{D.3 Radiation}

Radiation is the energy of the radiation field is transported by electromagnetic waves (or photons) as a result of the changes in the electronic configurations of the atoms or molecules. Radiation transfer occurs most efficiently in a vacuum [5].

$q_{\text {rad }}=\varepsilon \sigma\left(T_{s}^{4}-T_{\text {sur }}^{4}\right)$

\section{E. Thermal Insulation}

Thermal insulation is currently the most common application of single or double walled pipe systems.In transporting crude oil through a piping system, it is imperative to keep the temperature of the crude oil above its freezing point. If the temperature low, it could make crude oil freeze and cause the deposition in the pipe.

\section{E.1 Insulation Temperature Range}

Thermal insulation is further divided into three general application temperature ranges as follows:

A. Low Temperature Thermal Insulation

1. $5^{\circ} \mathrm{C}$ through $0^{\circ} \mathrm{C}$ - i.e. Cold or chilled water.

2. $0^{\circ} \mathrm{C}$ through $-40^{\circ} \mathrm{C}$ - i.e. Refrigeration or glycol.

3. $-40^{\circ} \mathrm{C}$ through $-75^{\circ} \mathrm{C}$ - i.e. Refrigeration or brine.

4. $-75^{\circ} \mathrm{C}$ through $-275^{\circ} \mathrm{C}$ (absolute zero) - i.e. Cryogenic.

B. Intermediate Temperature Thermal Insulation

1. $16^{\circ} \mathrm{C}$ through $100^{\circ} \mathrm{C}$ - i.e. Hot water and steam condensate.

2. $100^{\circ} \mathrm{C}$ through $315^{\circ} \mathrm{C}$ - i.e. Steam, high temperature hot water. 
C. High Temperature Thermal Insulation

1. $315^{\circ} \mathrm{C}$ through $815^{\circ} \mathrm{C}$ - i.e. Turbines, breechings, stacks, exhausts, incinerators.

E.2 Insulating Materials Hot and Cold Application

A. Polyurethane Foam

A polyurethane foam insulation layer is made by blowing the polyurethane with $\mathrm{CO} 2$, N2, or water and isone of the most common PIP insulation materials. The density of the foam can be controlled. The thermal conductivity of foams is proportional to the density of the foams. For high density, which means high conductivity and low insulation performance but greater strength, 3.0-6.0 pcf polyurethane foam expanded with a $\mathrm{CO} 2$ blowing agent is a typical insulation material for a PIP system. PIP systems with a PUF insulation layer have been successfully installed with both S-lay and Jlay methods [6].

\section{F. ANSYS CFD (Computational Fluid Dynamic)}

ANSYS CFD software delivers well validated results that closely match product performance in the real world. With ANSYS CFD, it can perform multiphysics analysis, including fluid forces, thermal effects, structural integrity and electromagnetic radiation, to assess and fully optimize the product [7].

\section{G. Theory of Fluid Flow}

\section{G.1 Laminar Flow}

Laminar flow is encountered when highly viscous fluids such as oils flow in small pipes or narrow passages.Thelaminar flow characterized by smooth streamlines and highly ordered motion. In fully developed laminar flow, each fluid particle moves at a constant axial velocity along a streamline and the velocity profile $u(r)$ remains unchanged in the flow direction.

\section{G.2 Turbulent Flow}

Most flows encountered in practice are turbulent. It is characterized by velocity fluctuations and highly disordered motion. turbulent flow is a complex mechanism dominated by fluctuations, and despite tremendous amounts of work done in this area by researchers, the theory of turbulent flow remains largely undeveloped.

As a result, turbulent flow is associated with much higher values of friction, heat transfer, and mass transfer coefficients [8].

\section{H. General of Crude Oil Temperature}

Crude oil is a complex mixture of many different chemical components, mainly organic compounds (hydrocarbons) which usually make up about 95\% of it. The remaining compounds of crude oil are made up of small amounts of oxygen, nitrogen, sulfur and small amount of metals such as iron, vanadium, nickel and chromium.

The temperature of crude oil when reaches the surface of the wellhead is 100 - 120 degrees F. And the temperature at the end of the flow pipe was 220 degrees $F$ [9].

\section{General of Subsea Temperature}

There is a barrier between the surface water and deeper layers of the ocean that are not mixed. The barrier begins around 100 meters and can extend another few hundred meters downwards. There is a thermo cline meaning there is a quick change in temperature when entering the deeper surface of water. A CTD (Conductivity, Temperature and Depth) instrument (usually placed in the water from a ship or a platform) measures temperature in the deep ocean. Recordings have shown that the average temperature of water ranges from 0-3 degrees Celsius (32-37.5 degrees Fahrenheit) [10].

\section{RESULTS \& DISCUSSION}

\section{A. Pipe Data}

The pipe data collection is done by collecting from literature study (journal) with the tittle “ Review on Deep Water Flowlines of Gumusut - Kakap, Malaysia” by J. Koto from Departemen of Aeronautical, Automotive and Ocean Engineering, University Teknologi Malaysia, and Ocean and Aerospace Engineering Research Institute, Indonesia, and from the design pipe calculation. Here is the data that will be used in this bachelor thesis, there are: 
International Journal of Marine Engineering Innovation and Research, Vol. 2(3), June. 2018. 199-209

Table 3.1 Pipeline data and Design Pipe Data

\begin{tabular}{lll}
\hline \multicolumn{3}{c}{ Pipeline Data } \\
\hline Parameter & Value & Units \\
\hline Pipe Material Grade & API 5L X65 & \\
Steel Density & 7850 & $\mathrm{Kg} / \mathrm{m} 3$ \\
Diameter OD & 203.2 & $\mathrm{~mm}$ \\
SMYS & 448 & $\mathrm{MPa}$ \\
SMTS & 530 & $\mathrm{MPa}$ \\
Poissons Ratio (v) & 0.3 & $\mathrm{MPa}$ \\
Young's Modulus (E) & 207000 & $\mathrm{MPa}$ \\
Thermal Expansion Coef. (a) & $1.17 x 10 \mathrm{E}-05$ & $/ \mathrm{C}$ \\
Pipe Fab. Types & Seamless & \\
Length Pipe & 12 (1 section) & $\mathrm{m}$ \\
\hline
\end{tabular}

Operating Design Data

\begin{tabular}{lll}
\hline Parameter & Value & Units \\
\hline Design Pressure & 6000 & $\mathrm{MPa}$ \\
Max. Allowable Operating Pressure (MAOP & 10000 & $\mathrm{MPa}$ \\
Operating Temperature & $372(99 \mathrm{C})$ & $\mathrm{K}$ \\
Content Density & 855 & $\mathrm{Kg} / \mathrm{m} 3$ \\
Flow Rate & 150000 & $\mathrm{BPOD}$ \\
Corrosion Allowance & 5 & $\mathrm{~mm}$ \\
Target Life Pipe & 50 & years \\
\hline
\end{tabular}


International Journal of Marine Engineering Innovation and Research, Vol. 2(3), June. 2018. 199-209

Environment Data

\begin{tabular}{lll}
\hline Parameter & Value & Units \\
\hline Water Depth & 1200 & $\mathrm{~m}$ \\
Seawater Temperature & $278(5 \mathrm{C})$ & $\mathrm{K}$ \\
Seawater Density & 1027 & $\mathrm{Kg} / \mathrm{m} 3$ \\
Max Wave Height & 2 & $\mathrm{~m}$ \\
Max Wave Period & 5 & $\mathrm{~s}$ \\
Seabed Friction & 0.58 & - \\
\hline
\end{tabular}

Design Factor

\begin{tabular}{|c|c|c|}
\hline Parameter & Value & Source \\
\hline $\begin{array}{l}\text { Internal Pressure (Burst) Design } \\
\text { Factor }\end{array}$ & $\mathrm{fd}=0.75$ & API RP 1111 Sect. 4.3 .1 \\
\hline $\begin{array}{l}\text { Hydrotest Hoop Stress Design } \\
\text { Factor }\end{array}$ & $\mathrm{fh}=0.9$ & API RP 1111 Sect. 4.3 .1 \\
\hline Weld Joint Factor & $\mathrm{fe}=1.0$ & API RP 1111 Sect. 4.3.1 \\
\hline External Collapse-Seamless Pipe & fo $=0.7$ & API RP 1111 Sect. 4.3.2.1 \\
\hline $\begin{array}{l}\text { Collapse Factor Combined Bending } \\
\text { Strain and External Pressure - } \\
\text { Seamless Pipe }\end{array}$ & $\mathrm{fc}_{\mathrm{c}}=0.7$ & API RP 1111 Sect. 4.3.2.2 \\
\hline Propagating Buckle Design Factor & $\mathrm{fp}=0.8$ & API RP 1111 Sect. 4.3.2.3.2 \\
\hline Temperature Derating Factor & $\mathrm{ft}=1$ & $\begin{array}{l}\text { ASME B31.8 Table } \\
\text { 841.1.8-1 }\end{array}$ \\
\hline Max. Installation Bending Strain & $\varepsilon 1=0.15 \%$ & $\begin{array}{l}\text { API RP } 1111 \text { Appendix D, } \\
\text { Sect. D.4 }\end{array}$ \\
\hline Max. In-Place Bending Strain & $\varepsilon 2=0.15 \%$ & $\begin{array}{l}\text { API RP } 1111 \text { Appedix D, } \\
\text { Sect. D.4 }\end{array}$ \\
\hline $\begin{array}{l}\text { Bending Safety Factor Installation } \\
\text { Bending plus External Pressure }\end{array}$ & $\mathrm{f} 1=2$ & API RP 1111 Sect. 4.3.2.2 \\
\hline $\begin{array}{l}\text { Bending Safety Factor In-Place } \\
\text { Bending plus External Pressure }\end{array}$ & $\mathrm{f} 2=2$ & API RP 1111 Sect. 4.3.2.2 \\
\hline
\end{tabular}


Wall Thickness and Material Grade Verification Result Data

\begin{tabular}{lll}
\hline Parameter & Value & Units \\
\hline Outer Diameter of Pipe & 203.2 & $\mathrm{~mm}$ \\
Length of Pipe & $12(1$ section $)$ & $\mathrm{m}$ \\
Wall Thickness without Corrosion Allowance & 12.393 & $\mathrm{~mm}$ \\
Wall Thickness Require & 18.393 & $\mathrm{~mm}$ \\
Inner Diameter of Pipe & 166.414 & $\mathrm{~mm}$ \\
Pipe Material Grade & API X 65 & \\
Pipe Fabrication & Seamless & \\
Pressure containment & 87.94 & $\mathrm{MPa}$ \\
Collapse & 8.26 & $\mathrm{MPa}$ \\
Propagation Buckling & 10.452 & $\mathrm{MPa}$ \\
Status & OK & \\
\hline
\end{tabular}

On Bottom Stability Result Data

\begin{tabular}{lll}
\hline Parameter & Value & Units \\
\hline Overall Area of Linepipe & 0.068 & $\mathrm{~m}^{2}$ \\
Concrete Density & $3.197 .10^{3}$ & $\mathrm{Kg} / \mathrm{m}^{3}$ \\
Cut Back Weight & 6.241 & $\mathrm{Kg} / \mathrm{s}^{2}$ \\
Bouyancy & 680 & $\mathrm{Kg} / \mathrm{s}^{2}$ \\
Submerged Weight & 664.485 & $\mathrm{Kg} / \mathrm{s}^{2}$ \\
Average velocity current across the pipe & 0.208 & $\mathrm{~m} / \mathrm{s}$ \\
\hline
\end{tabular}

\begin{tabular}{|c|c|c|c|c|c|c|c|}
\hline Case & Case & $\begin{array}{l}\text { Concrete } \\
\text { Thickness }\end{array}$ & $\begin{array}{l}\text { Lateral Stab } \\
\text { Requiremen }\end{array}$ & & $\begin{array}{l}\text { Vertical Sta } \\
\text { Requiremen }\end{array}$ & & Remark \\
\hline 1 & $\begin{array}{l}\text { Description } \\
\text { Operating }\end{array}$ & $\begin{array}{l}(\mathrm{mm}) \\
40\end{array}$ & $\begin{array}{l}U C_{L} \\
5.185 \times 10^{-3}\end{array}$ & $\begin{array}{l}\text { Criteria } \\
<1\end{array}$ & $\begin{array}{l}U C_{V} \\
9165 \times 10^{-3}\end{array}$ & $\begin{array}{l}\text { Criteria } \\
<1\end{array}$ & $O K$ \\
\hline
\end{tabular}

Thermal Expansion Analysis Result Data

\begin{tabular}{ll}
\hline Parameter & Value \\
\hline Strain Due to Pressure End Cap $\left(\varepsilon_{\mathrm{E}}\right)$ & $3.288 \cdot 10^{-4}$ \\
Strain due to Poisson Effect $\left(\varepsilon_{\mathrm{v}}\right)$ & $5.982 \cdot 10^{-4}$ \\
Thermal Strain $\left(\varepsilon_{\mathrm{T}}\right)$ & $1.493 \cdot 10^{-5}$ \\
Frictional Resistance $\left(\varepsilon_{\mathrm{f}}\right)$ & $3.607 .10^{-6}$ \\
Total Applied Strain & $9.455 \cdot 10^{-4}$ \\
Anchor Point & $3.145 \cdot 10^{3} \mathrm{~m}$ \\
Pipeline Expansion & $1.487 \mathrm{~m}$ \\
\hline
\end{tabular}

Cathodic Protection Result Data

\begin{tabular}{lll}
\hline Parameter & Value & Units \\
\hline Current Density & 0.107 & $\mathrm{~A} / \mathrm{m}^{2}$ \\
Current Demand & 0.04 & $\mathrm{~A}$ \\
Total Anode Net Mass & 6.89 & $\mathrm{~kg}$ \\
Required Anode Length & 162.293 & $\mathrm{Mm}$ \\
Final Anode Thickness & $5.614 \times 10^{-4}$ & $\mathrm{~m}^{3}$ \\
Final Anode Current Output & 0.782 & $\mathrm{~A}$ \\
Coating Breakdown Factor & & \\
CBF for pipeline & 35 & $\%$ \\
CBF for Field Joint Coating & 60 & $\%$ \\
Combine CBF & 4.913 & $\%$ \\
\hline
\end{tabular}


Allowable Free Span Result Data

\begin{tabular}{lll}
\hline Parameter & Value & Units \\
\hline Yield Strength $\left(\mathrm{f}_{\mathrm{y}}\right)$ & 343.68 & $\mathrm{MPa}$ \\
Tensile Strength $\left(\mathrm{f}_{\mathrm{u}}\right)$ & 422.4 & $\mathrm{MPa}$ \\
Pressure Containment Resistance $\left(\mathrm{P}_{\mathrm{b}} \mathrm{t}\right)$ & 56.005 & $\mathrm{MPa}$ \\
& $5.21 \times 10^{5}$ & $\mathrm{~N} . \mathrm{m}$ \\
Bending Moment & $2.745 \times 10^{6}$ & $\mathrm{~N}$ \\
\hline
\end{tabular}

B. Characteristic of Crude Oil Data

In this bachelor thesis, the characteristic data of crude oil will be used as fluid which is the flowof that crude oil expected to remain stable. Here are the characteristic data of crude oil:

Table 3.2 Characteristic of Malaysian Crude Oil Data

\begin{tabular}{lll}
\hline Parameter & Value & Units \\
\hline Flowrate & 150000 & $\mathrm{BOPD}$ \\
Density & 855 & $\mathrm{~kg} / \mathrm{m}^{3}$ \\
Specific Heat Coef. & 2130 & $\mathrm{~kJ} / \mathrm{kg} \mathrm{K}$ \\
Thermal Conductivity & 0.159 & $\mathrm{~W} / \mathrm{m} \mathrm{K}$ \\
Kinematic Viscosity & $3.8 \mathrm{E}-07$ & $\mathrm{Kg} / \mathrm{m} . \mathrm{s}$ \\
\hline
\end{tabular}

\section{Simulation Concept}

In this paper, the simulation to knowing the impact of double walled pipe to crude oil flow which under the sea with depth $1200 \mathrm{~m}$. The simulation will be using pipe size that was designed by author and from the data . pipe has inner diameter pipe is 6.552 inch and length is $12 \mathrm{~m}$ (as pipe) and $19 \mathrm{~m} \mathrm{x} 19 \mathrm{~m}$ (as seawater area). Because the supporting software that will be used for simulation couldn't portray the average path along the existing pipeline in offshore industry, which the length is $1000 \mathrm{~m}$ or more, so it will only use one section length pipe.Then will do variations about the thickness of the insulation layer and diameter of second pipe which are expected to give an impact to reduce the heat loss, so the flow of crude oil keep steady. Here is the variations size of the thickness of insulation layer and diameter of second pipe:

\section{a. Variation 1}

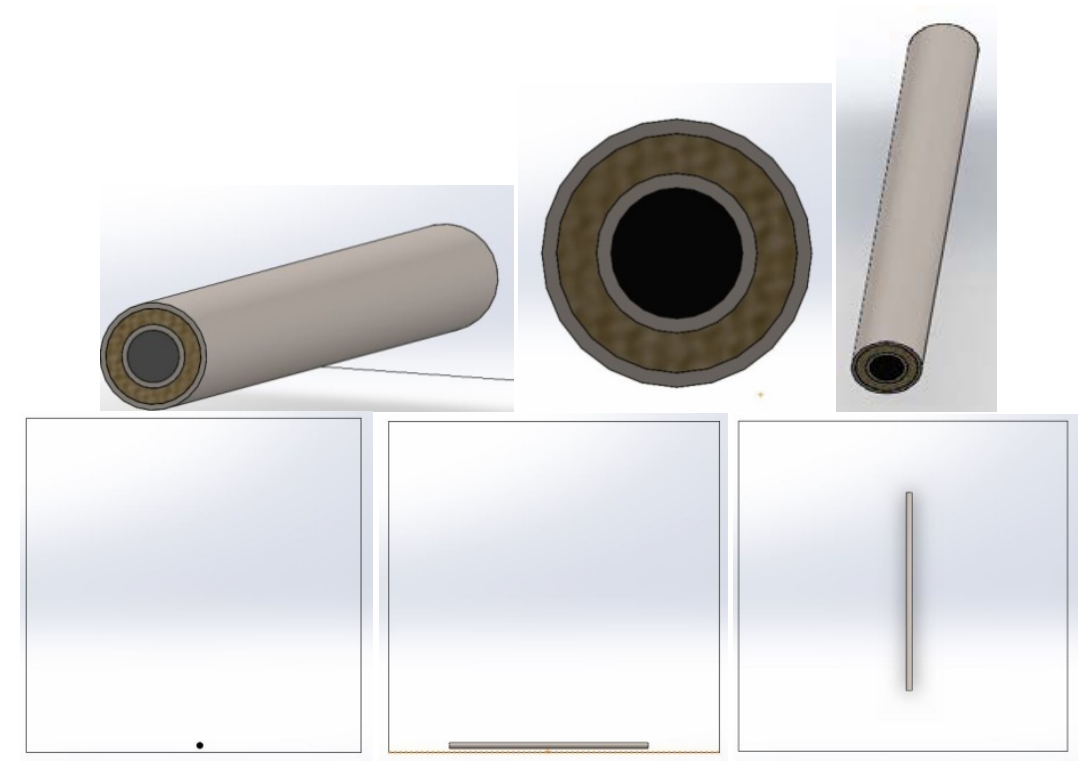

Fig. 3.1 Pipe Variation 1

Figure above is the 3D model of variation 1 with inner diameter of the first pipe is 6.552 inch, insulation layer 4 inch, and the diameter of the second pipe is 13.448 inch. 
b. Variation 2

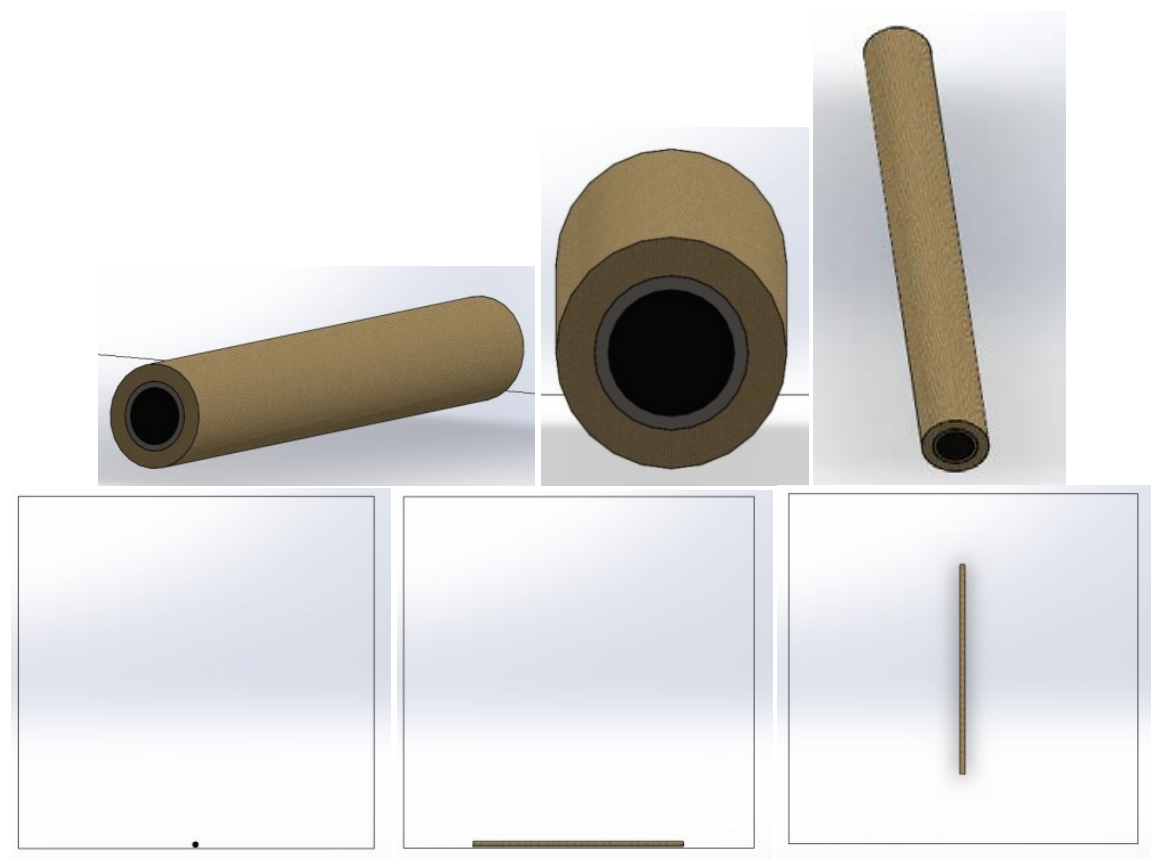

Fig. 3.2 Pipe Variation 2

Figure above is the 3D model of variation 3 with inner diameter of the first pipe is 6.552 inch, insulation layer 4 inch, and doesn't use the second pipe.

\section{c. Variation 3}

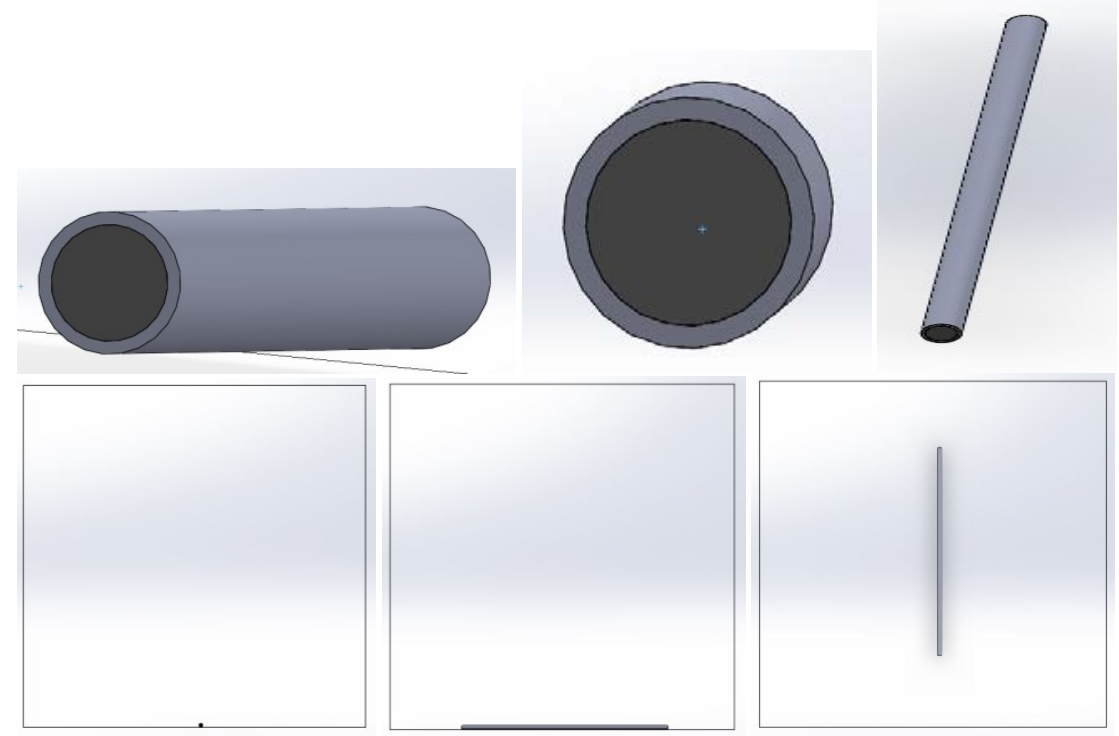

Fig, 3.3 Pipe Variation 3

Figure above is the 3D model of variation 4 with inner diameter of the first pipe is 6.552 inch and doesn’t use insulation layer nor second pipe. 
D. Result and Analysis of CFD Simulation

The result of CFD Simulation in three pipe variation has the different of each types, there are:

\section{a. Variation 1}

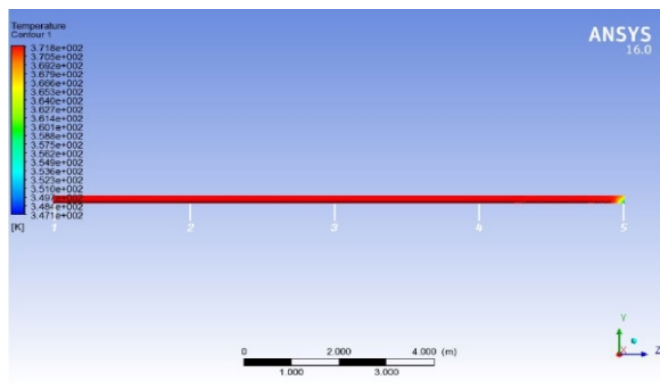

Crude oi1 Temperature

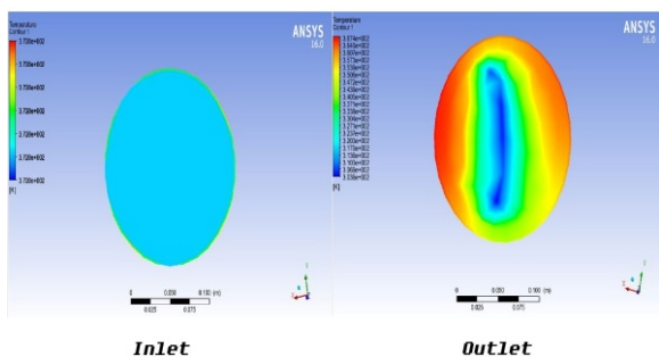

Fig. 3.4 Crude Oil Result Variation 1

Based from the result report of simulation using CFD software obtained that the result of design pipe in first variation, are:

In the first variation of pipe design above, it shows that the heat distribution is stable, this is shown in Figure 4.4, with the temperature difference in the output decreasing periodically, to a maximum decrease in temperature of $24.911 \mathrm{~K}$ from the initial temperature of
$372 \mathrm{~K}$. So the heatloss in the first variation of pipe design is only occurs at the end of the pipe or outlet the oil.Then the effect of using double pipe on first variation of petroleum flow at sea depth $1200 \mathrm{~m}$ is, it's able to stabilize the flow of petroleum, due to temperature of petroleum stable and only decreasing maximum temperature until $24.911 \mathrm{~K}$. So the possibility of waxbuild up on this variation of pipe design is minimal.

\section{b. Variation 2}
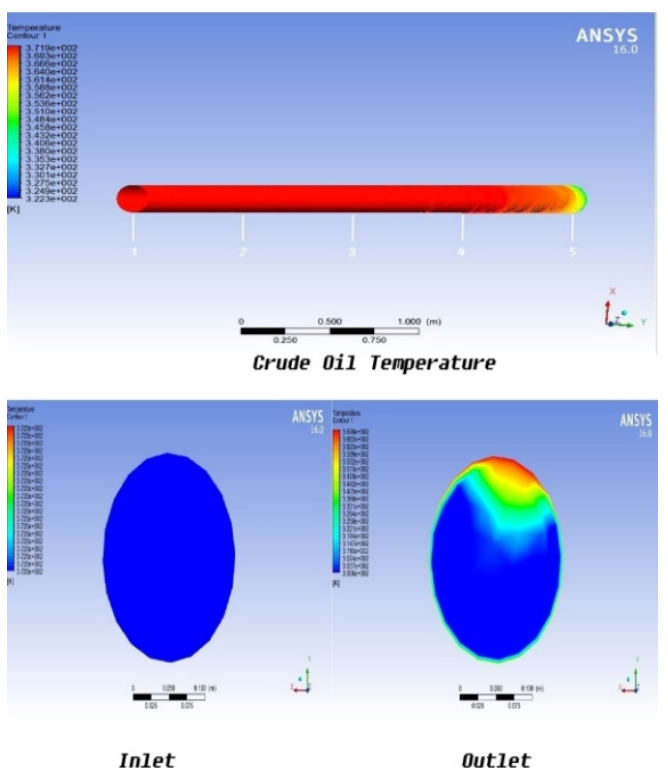

Fig. 3.5 Crude Oil Result Variation 2

Based from the result report of simulation using CFD software obtained that the result of design pipe in third variation, are:

In the second variation of pipe design above, it shows that the heat distribution is stable, this is shown in Figure 4.5, with the temperature difference in the output that decreases periodically to a maximum decrease in temperature of $36 \mathrm{~K}$ from the initial temperature of 372 $\mathrm{K}$. So the heat loss in the design of this second variation begin to occur in area4 to end of pipe or oil outlet (area 5). 
So the effect of using single pipe with insulation on second variation to petroleum flow at sea depth $1200 \mathrm{~m}$ is able to stabilize oil flow, but in area 4, petroleum temperature has decreased.

\section{c. Variation 3}

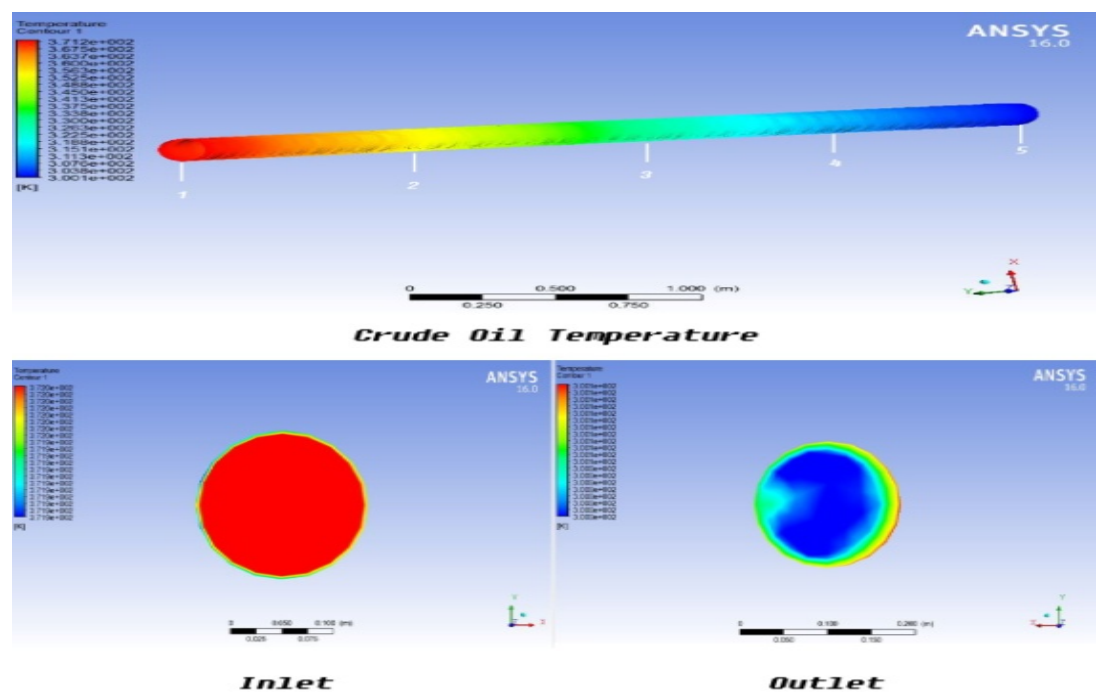

Fig. 3.6 Crude Oil Result Variation 3

Based from the result report of simulation using CFD software obtained that the result of design pipe in fifth variation, are:

In the third variation of pipe design above, the variation shows that the heat distribution is less stable, this is shown in Figure 4.6, with the temperature difference in the output decreasing periodically to the maximum $72 \mathrm{~K}$ temperature drop from the initial temperature of $372 \mathrm{~K}$. So the heatloss in the first variation design has started to occur in area 1 to the tip of the pipe or oil output (area 5).

So the effect of using single pipe on the third variation of petroleum flow at sea depth $1200 \mathrm{~m}$ is less able to stabilize the flow of petroleum, because petroleum temperature has started to decrease at area 1 with maximum temperature up to $72 \mathrm{~K}$.

\section{CONSCLUSION}

The conclusion based on simulation and analysis, are: 1. Before the simulation and analysis of the impact of a pipe on the flow of crude oil for under-sea piping system, pipe designing is needed to be done first to find out:

- $\quad$ Pipe Diameter

- Wall thickness and Material Grade Verification

- Internal Pressure Containment

- Collapse due to External Pressure

- Buckling due to Combined Bending and External Pressure

- Propagation Buckling

- On Bottom Stability Design

- Pipeline Vertical Stability

- Absolute Lateral Static Stability Method

- Pipe Soil Interaction

- $\quad$ Pipeline Strain

- $\quad$ Cathodic Protection Verification

- Anode Calculation

- Anode Spacing

- Allowable Free Span Calculation
- Analysis Cases

- Static Stress Criteria

2. In the simulation process, the authors use two software,there are Solid Work to create 3D pipe form and ANSYS to simulate the effect of pipe that has been designed to influence the flow of crude oil.

3. By using double walled pipe it can be seen that the effect on crude oil flow remains stable due to heat distribution occurring in the pipe is very evenly until the end of pipe or outlet. It is indicated by the decrease of temperature of crude oil which is small, with the value of $24,911 \mathrm{~K}$. So that the heatloss that occurs on this pipe is smaller than single pipe, automatically for the occurrence of waxbuild up on this pipe is very minimal though at a depth of $1200 \mathrm{~m}$.

\section{REFERENCES}

[1] Venture Engineering \& Construction, "Double Walled Piping System”, p. 1, Pittsburgh.

[2] About Pipelines, "Would double walled pipelines help prevent spills?”, 2016, Available: https://www.aboutpipelines.com/blog/would-double-walledpipelines-help-prevent-spills/.

[3] Mark Carruth, "Design Optimization Case Study: Deep Sea Linepipe”, University of Cambridge, pp. 1-8.

[4] Qiang Bai, Young Bai, "Subsea Pipeline Design, Analysis, and Installation”, 2014, Houston USA.

[5] Yunus A. Cengeland Michael A. Boles, "Thermodynamics: An Engineering Approach Fifth Edition”, McGraw-Hill, 2006, pp. 93- 5.

[6] Michael Kelly, "Pipe Insulation (Hot \& Cold) Material Selection \& Application”, TRADE OF Industrial Insulation, Phase 2, pp. 3-6, 2014

[7] http://www.ansys.com/products/fluids.

[8] cen72367_ch08.qxd, "Flow In Pipes”, University of San Carlos, 2004

[9] Kevin Cooke, “ What is the average temperature of crude oil when it is extracted", Quora, 2015, Available: https://www.quora.com/What-is-the-average-temperature-ofcrude-oil-when-it-is-extracted.

[10] Abraham K. George and Ram N Singh and SayyadulArafin, "Equation of State of Crude Oil Samples", 2013 